\title{
Implementasi Model Delphi dalam Pengembangan Multimedia Interaktif Pengenalan Objek Wisata di Kabupaten Banyuwangi
}

\author{
Muhammad Rusli ${ }^{1}$, Khairul Anam², Dian Rahmani Putri ${ }^{3}$ \\ Institut Teknologi dan Bisnis (ITB) STIKOM Bali \\ e-mail: ${ }^{1}$ rusli@stikom-bali.ac.id, ${ }^{2}$ irularul10@ gmail.com, ${ }^{3}$ rahmani@ stikom-bali.ac.id \\ Diajukan: 28 November 2019; Direvisi: 29 November 2019; Diterima: 29 November 2019
}

\begin{abstract}
Abstrak
Selaras dengan perkembangan infrastruktur teknologi informasi, khususnya teknologi multimedia, kebutuhan informasi yang aktual, menarik dan interaktif menjadi suatu keniscayaan untuk dipenuhi. Informasi tersebut dibutuhkan antara lain guna mengenalkan atau mempromosikan objek-objek wisata bagi para wisatawan baik domestik maupun mancanegara. Untuk dapat lebih mempromosikan objek-objek wisata sebuah daerah kepada wisatawan secara luas, cepat dan menarik, diperlukan penggunaan aplikasi teknologi multimedia tepat guna yang sesuai dengan kebutuhan dan tuntutan di era digital ini, yaitu berupa informasi wisata yang dikemas dalam sebuah format multimedia. Tujuan penelitian ini adalah menghasilkan sebuah aplikasi multimedia interaktif yang berisikan informasi tentang objek wisata yang ada di Kabupaten Banyuwangi. Metode pengembangannya menggunakan Model Delphi dengan software Authoring Multimedia menggunakan Adobe Flash. Prinsip-prinsip animasi dalam menampilkan elemen-elemen multimedia diterapkan guna memperoleh hasil yang lebih menarik dan efektif. Hasil pengembangannya berupa produk multimedia interaktif pengenalan objek wisata di Kabupaten Banyuwangi berbasis Android.
\end{abstract}

Kata kunci: Objek Wisata Banyuwangi, Multimedia Interaktif, Prinsip Animasi, Model Delphi, Android.

\begin{abstract}
In line with the development of information technology infrastructure, especially multimedia technology, the actual, interesting and interactive information needs become a necessity to be fulfilled. The information is needed, among others, to introduce or promote tourist objects for both domestic and foreign tourists, broadly, quickly and attractively. It is necessary to use appropriate multimedia technology applications that are following the needs and demands of this digital era, namely in the form of tourist information packaged in a multimedia format. The purpose of this study is to produce an interactive multimedia application that contains information about attractions in Banyuwangi Regency. The development method uses the Delphi Model with Multimedia Authoring software using Adobe Flash. The principles of animation in displaying multimedia elements are applied in order to obtain more interesting and effective results. The results of the development are in the form of interactive multimedia products introducing tourism objects in Banyuwangi regency based on Android.
\end{abstract}

Keywords: Banyuwangi Tourism Object, Interactive Multimedia, Delphi Model, Android.

\section{Pendahuluan}

Pariwisata atau turisme merupakan perjalanan yang dilakukan oleh seseorang atau sekelompok orang dalam jangka waktu tertentu dari sebuah tempat ke tempat lain dengan melakukan perencanaan sebelumnya, dan bertujuan untuk berekreasi atau memenuhi sebuah kepentingan tertentu. Kegiatan pariwisata berkembang luas hingga dapat melibatkan ribuan atau bahkan jutaan manusia, baik di kalangan pemerintah dan masyarakat dengan biaya yang relatif terjangkau. Perkembangan pariwisata menjadikan sektor pariwisata mengalami perubahan pola, bentuk, dan sifat kegiatan yang dapat menguntungkan berbagai pihak, baik masyarakat, pengelola pariwisata dan juga pemerintah pusat dan daerah [1].

Teknologi merupakan hal yang sangat penting bagi kehidupan manusia, salah satu jenis teknologi yang telah berkembang sangat pesat dan dimanfaatkan dengan baik di era digital, yaitu teknologi informasi yang di dalamnya mencakup teknologi multimedia. Terapan teknologi informasi telah berkembang pesat 
pada berbagai bidang antara lain pertanian, industri, perdagangan, dan pariwisata. Pada bidang pariwisata, khususnya untuk promosi dan pengenalan objek wisata, peranan teknologi informasi maupun multimedia telah memberikan kontribusi yang sangat signifikan sehingga dalam mempromosikan dan mengenalkan objek-objek wisata sebuah daerah dapat dilakukan dengan lebih cepat, lebih mudah, dan dengan biaya yang relatif terjangkau, serta memiliki jangkauan yang luas. Multimedia interaktif sebagai salah satu produk dari teknologi multimedia, memungkinkan calon wisatawan memperoleh output dalam bentuk yang lebih menarik dan interaktif dibandingkan dengan media elektronik yang lain. Calon pengunjung atau wisatawan yang memanfaatkan teknologi multimedia interaktif untuk memperoleh informasi pariwisata dapat memperoleh gambaran yang jelas atas informasi yang diinginkan [2].

Banyuwangi merupakan salah satu kabupaten yang berada di ujung paling timur provinsi Jawa Timur. Daerah ini memiliki aneka pemandangan alam, di antaranya pantai dan pegunungan; serta kekayaan seni budaya, adat istiadat dan tradisi. Data kunjungan wisatawan yang dilansir dari Radar Banyuwangi tahun 2017, jumlah kunjungan wisatawan domestik 4,6 juta orang dan mancanegara 92 ribu orang; dan pada tahun 2018 jumlah kunjungan wisatawan domestik 4,9 juta orang dan mancanegara 100 ribu orang [3]. Jumlah kunjungan tersebut belum mengalami perubahan yang berarti atau memenuhi harapan berbagai pihak, khususnya Pemerintah Daerah. Setelah memperhatikan potensi kekayaan sumber daya alam yang ada, dilihat bahwa perlu untuk menampilkan keanekaragaman objek wisata beserta keindahan dan lokasinya ke dalam sebuah media informasi dan promosi berupa multimedia interaktif berbasis Android. Multimedia pengenalan tersebut dapat dikategorikan sebagai bagian dari multimedia pembelajaran dalam konteks tujuan pembelajaran yang berada pada level yang terbawah dari taksonomi bloom, yakni untuk tujuan pengenalan [4].

Multimedia interaktif pengenalan objek wisata Kabupaten Banyuwangi ini memiliki fitur-fitur yang dapat menampilkan lokasi, foto, video, petunjuk arah, penginapan, harga tiket masuk, dan beberapa fasilitas lainnya. Dengan adanya multimedia interaktif berbasis Android tersebut, objek-objek wisata yang ada di daerah Banyuwangi diharapkan dapat lebih dikenal dan banyak dikunjungi para wisatawan baik domestik maupun mancanegara.

Penelitian ini merupakan penelitian pengembangan, yaitu mengembangkan multimedia interaktif pengenalan objek wisata di Kabupaten Banyuwangi. Metode pengembangan multimedianya menggunakan model Delphi. Model Delphi, nama yang berasal dari Oracle of Delphi, adalah sebuah sistem komunikasi terstruktur, yang bertujuan untuk mengurangi rentang proses respons dan mencapai sesuatu yang lebih dekat dengan konsensus para ahli. Pada awalnya merupakan sebuah metode peramalan interaktif dan sistematis yang diciptakan dari serangkaian keahlian. Model Delphi ini dikembangkan oleh sebuah proyek non-profit yang digagas oleh Douglas Aircraft Company di Amerika, yang dinamai RAND Corporation (Research and Development) pada tahun 50an [5]. Di masa sekarang model ini dikembangkan untuk membuat multimedia pembelajaran [6]. Dalam perjalanannya, model pengembangan multimedia ini telah dijabarkan dengan lebih lengkap oleh [7]. Dengan mengimplementasikan model ini, diharapkan produk yang dihasilkan, melalui tahapan-tahapan yang ada, dalam pengembangan multimedia interaktif pengenalan objek-objek wisata di kabupaten Banyuwangi akan efektif dan selaras dengan tujuan pembangunan/pengembangannya. Agar produk multimedia yang dihasilkan lebih menarik, visualisasi kontennya menggunakan prinsip-prinsip animasi dalam format multimedia [8][7].

\section{Tinjauan Pustaka}

\subsection{Sejarah dan objek-objek wisata Banyuwangi \\ 2.1.1. Sejarah Banyuwangi}

Sejarah Banyuwangi berhubungan dengan sejarah Kerajaan Blambangan ada pada abad ke-17. Banyuwangi merupakan bagian dari Kerajaan Hindu Blambangan yang dipimpin oleh Pangeran Tawang Alun. Pada masa ini VOC (Pemerintahan Belanda) menguasai secara administratif Kerajaan Blambangan atas dasar penyerahan kekuasaan Jawa bagian timur (termasuk Blambangan) dari Pakubuwono II kepada VOC.

Menurut tradisi lisan yang ada di daerah itu, nama Banyuwangi adalah terkait dengan peristiwa yang berhubungan dengan seorang permaisuri yang bernama Putri Sri Tanjung. Ia telah memiliki seorang suami yang dikenal bernama Raden Banterang. Putri Sri Tanjung diketahui telah hamil, namun kehamilannya diragukan oleh suaminya yang mengira anak atau janin yang ada di rahim istrinya adalah bukan anaknya. Raden Banterang menganggap istrinya telah melakukan perselingkuhan ketika ia sedang berada di medan perang. Atas dugaan tersebut, Raden Banterang membunuh istrinya di tepi sungai. Sebelum meninggal istrinya bersumpah bahwa ia tidak melakukan perselingkuhan, dan anak yang dikandungnya adalah anak dari Raden Banterang suaminya. Di samping itu, Putri Sri Tanjung menyatakan kepada suaminya bahwa, jika darah yang mengalir di sungai ini amis, maka berarti janin ini memang bukan 
anak Raden Banterang, tetapi jika berbau harum (wangi) maka janin ini adalah anak Raden Banterang. Maka seketika itu darah yang mengalir ke dalam sungai tersebut berbau wangi, dan karenanya Raden Banterang sebagai suami Putri Sri Tanjung sangat menyesal atas kejadian tersebut. Atas penyesalannya, sang suami memberikan nama daerah itu dengan nama Banyuwangi [9].

\subsubsection{Objek-objek Wisata}

Ada cukup banyak objek-objek wisata yang menarik dan berpotensi dikunjungi para wisatawan di Banyuwangi. Objek wisata yang ditampilkan pada multimedia mencakup objek-objek wisata yang dikelompokkan menjadi 9 kategori yakni: objek wisata pantai (Pulau Merah dan Teluk Ijo), pegunungan (Kawah Ijen), air terjun (Lider, Kembang Arum, dan Tirto Kemanten), hutan pinus (Pinus Songgon), sumber mata air jernih (Umbul Bening), dan rawa (Rowo Bayu) [3].

\subsection{Multimedia dan Interaktifitas Multimedia}

Multimedia didefinisikan sebagai media penyampaian informasi yang memiliki karakteristik berisi teks, grafis, animasi, video dan suara yang terintegrasi dan memuat konten yang terstruktur serta dapat disajikan secara berbeda [10].

Multimedia interaktif atau interaktivitas multimedia dideskripsikan sebagai berikut, yaitu antara lain tersedianya fasilitas guna: (1) memanipulasi objek-objek pada layar melalui aktivitas mouse, (2) bernavigasi secara linier, bergerak maju/mundur pada layar, (3) bernavigasi secara hierarki, berpindah ke situs/konten/slide tertentu, (4) bantuan interaktif, (5) umpan balik, (6) interaksi komunikatif, (7) interaksi konstruktif, dan (8) interaksi reflektif.

\subsection{Prinsip Animasi}

Ada 7 (tujuh) prinsip animasi dalam format multimedia [8][7]: (1) multimedia, belajar lebih baik dengan animasi dan narasi (audio) dari pada hanya dengan narasi saja; (2) persinggungan (contiguity), belajar lebih baik bila kata-kata disajikan dekat dengan porsi animasi (gambar) yang relevan dan juga bila porsi yang berhubungan narasi dan animasi disajikan bersamaan dari pada berturut-turut; (3) pertalian logis (coherence), belajar lebih baik dengan animasi dan narasi bila kata-kata (teks), suara, dan gambar yang berlebihan (tidak relevan) tidak disertakan; (4) modalitas, belajar lebih baik dengan animasi dan narasi dari pada animasi dan teks di layar (visual); (5) redundansi, belajar lebih baik dengan animasi dan narasi dari pada animasi, narasi, dan teks di layar; (6) segmentasi (segmentation) dan pretraining, belajar lebih baik bila tersedia fasilitas untuk mengelola pemrosesan yang esensial guna menghindari beban berlebih (overloading) pada sistem kognitifnya (tombol stop dan lanjut) dan juga bila diberikan sesi orientasi materi secara cepat (guna mengaktifkan pengetahuan awal) sebelum presentasi dimulai; dan (7) personalisasi, belajar lebih baik dari animasi dan narasi dengan gaya percakapan dari pada gaya formal.

\subsection{Model Delphi}

Model Delphi merupakan hasil review dan atau kajian beberapa pakar pada bidang yang relevan, terkait dengan model pengembangan multimedia yang efektif, terhadap literatur dan pengalamanpengalaman dalam pengembangan modul multimedia pembelajaran [6]. Beberapa literatur yang telah dikaji meliputi: (1) model-model pengembangan multimedia, (2) model-model desain pembelajaran, (3) modelmodel pengembangan software, dan (4) prinsip-prinsip multimedia pembelajaran.

Model ini terdiri 9 tahap, dan setiap tahapnya, telah dideskripsikan lebih detil meliputi hal-hal sebagai berikut [7]: (1) Mendefinisikan tujuan/target hasil penelitian/pengembangan, (2) me-review opsiopsi yang sudah ada (jika ada), (3) menentukan format output dan timeline, (4) menentukan konten/materi yang akan disampaikan, (5) mengembangkan flowchart, sitemap dan storyboard, (6) mengembangkan prototipe, (7) menguji/mengevaluasi formatif, (8) menyelesaikan desain, dan (9) menguji/evaluasi sumatif.

\section{Metode Penelitian/Pengembangan \\ 3.1. Pengumpulan Data}

Data diperoleh melalui studi literatur, wawancara, survei/kunjungan ke beberapa lokasi wisata yang menjadi target objek wisata di Banyuwangi. Target objek wisata meliputi 9 objek wisata yang tergolong dalam objek wisata pantai (Pulau Merah dan Teluk Ijo), pegunungan (Kawah Ijen), air terjun (Lider, Kembang Arum, dan Tirto Kemanten), hutan pinus (Pinus Songgon), sumber mata air jernih (Umbul Bening), dan rawa (Rowo Bayu) [3]. Data dapat berupa antara lain: petunjuk lokasi, karakteristik, gambar/foto, dan video objek-objek wisata.

Implementasi Model Delphi dalam Pengembangan Multimedia Interaktif Pengenalan Objek Wisata di Kabupaten Banyuwangi (Muhammad Rusli) 


\subsection{Metode Pengembangan Multimedia}

Dari data yang berhasil dikumpulkan (3.1), diterapkan langkah-langkah pengembangan multimedia pengenalan interaktif dengan mengimplementasikan tahapan-tahapan yang ada pada model Delphi [7]. Hasil implementasinya berupa sebuah prototipe multimedia pengenalan interaktif pengenalan objek-objek wisata di Kabupaten Banyuwangi.

\section{Hasil Penelitian dan Pembahasan}

\subsection{Hasil Penelitian atau Pengembangan}

Merujuk pada metode penelitian, hasil rancang bangun yang dapat ditampilkan sebagai berikut, yaitu struktur materi (Gambar 1), flowchart (Gambar 2), struktur menu sistem (Gambar 3), dan beberapa screenshot hasil aplikasi dan gambar lokasi wisata (Gambar 4 s.d Gambar 12).

Struktur materi memberikan gambaran tujuan pengenalan/pembelajaran atau kompetensi akhir yang diinginkan dalam mempelajari aplikasi ini (kotak teratas). Untuk memperoleh kompetensi akhir tersebut diperlukan pengetahuan-pengetahuan sebelumnya yang berada di bawahnya yang harus dipelajari lebih dahulu (kotak di sebelah bawah), demikian dan seterusnya sebagaimana struktur materi pada Gambar 1. Sementara flowchart menggambarkan struktur menu sistem secara umum (Gambar 2).

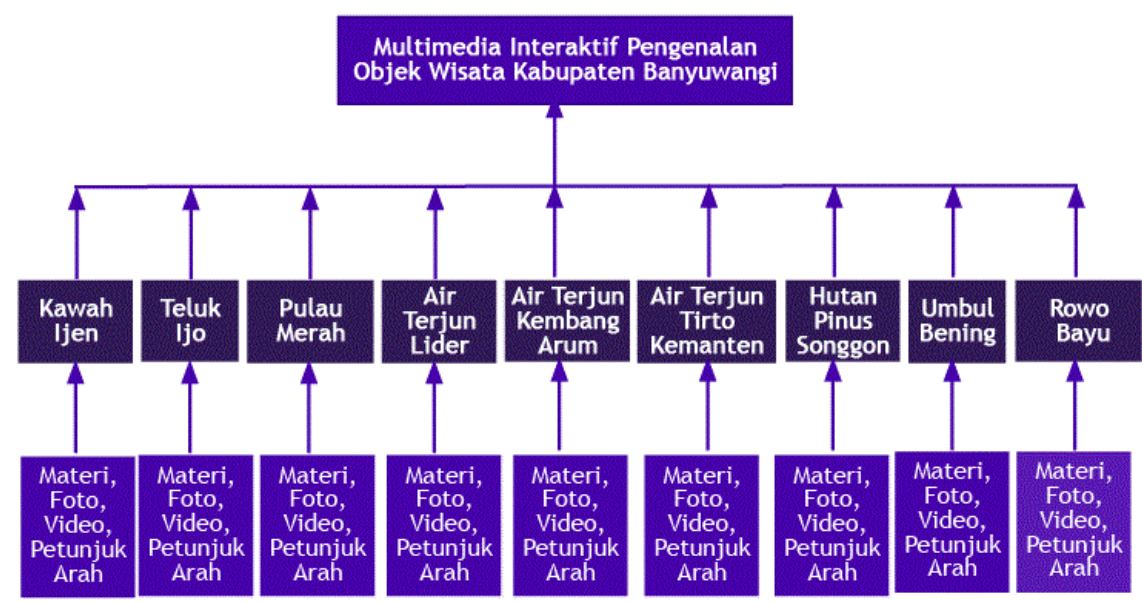

Gambar 1. Struktur materi.

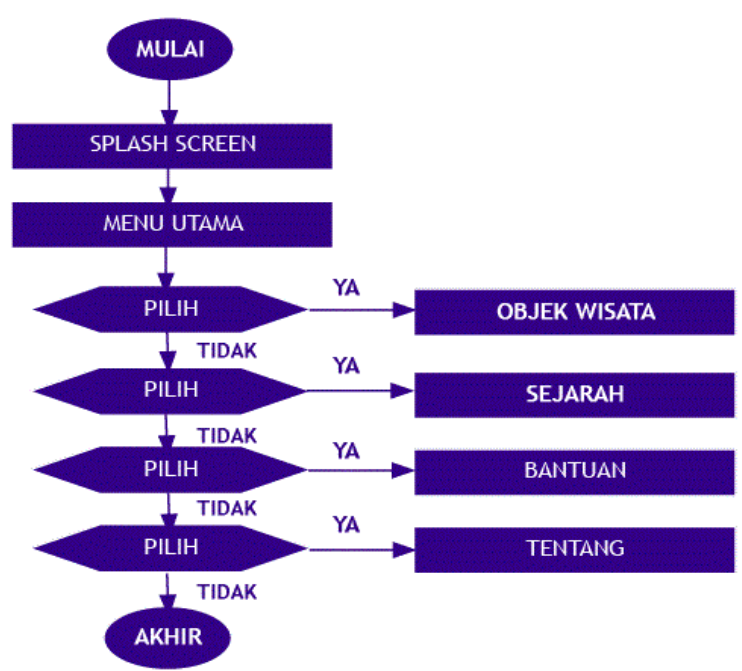

Gambar 2. Flowchart umum. 


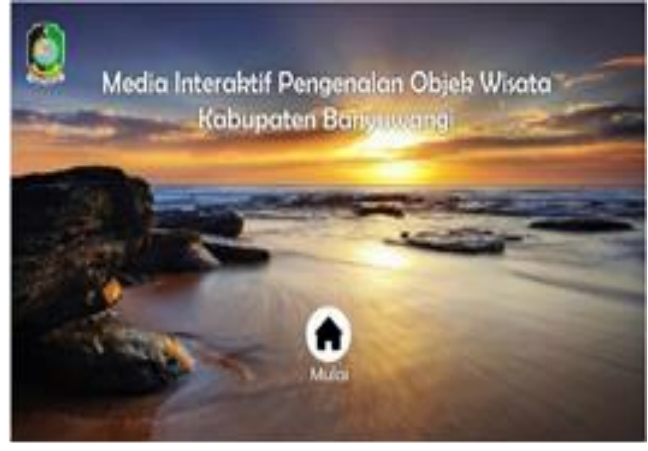

Gambar 3. Splash screen.

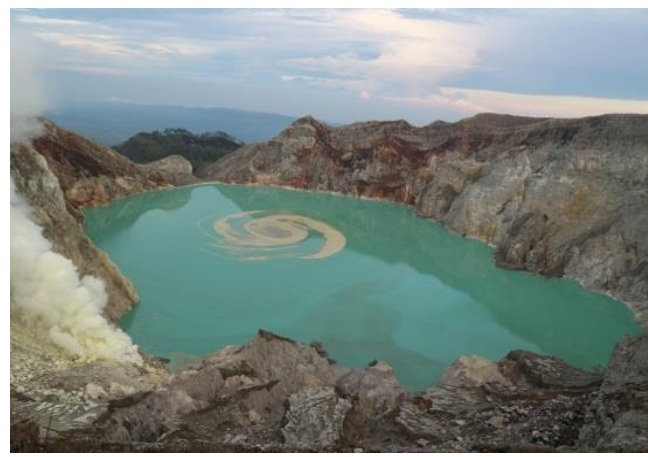

Gambar 5. Kawah Ijen.

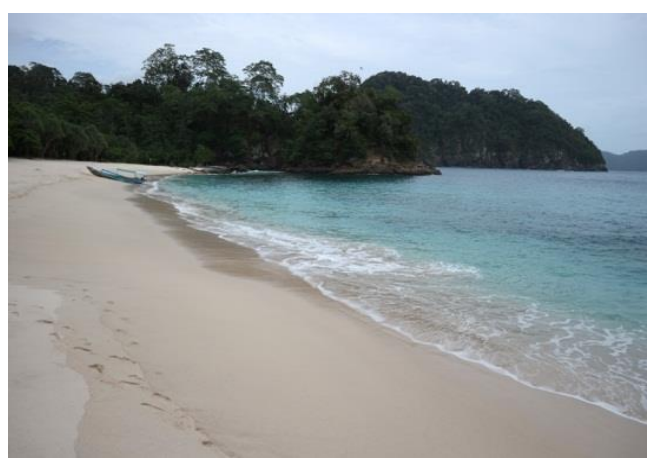

Gambar 7. Teluk Ijo.

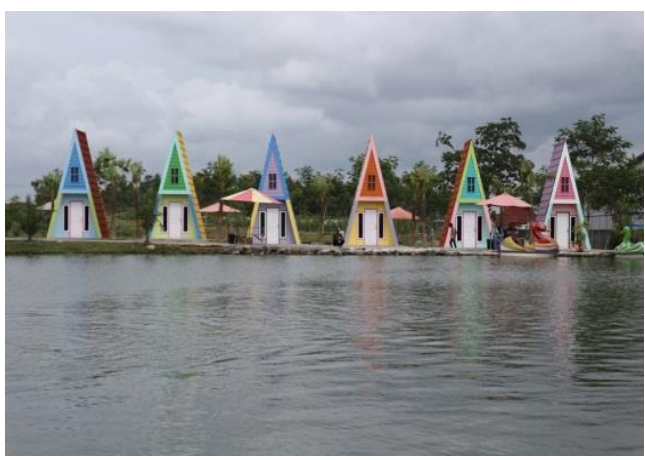

Gambar 9. Sumber Air Umbul Bening.

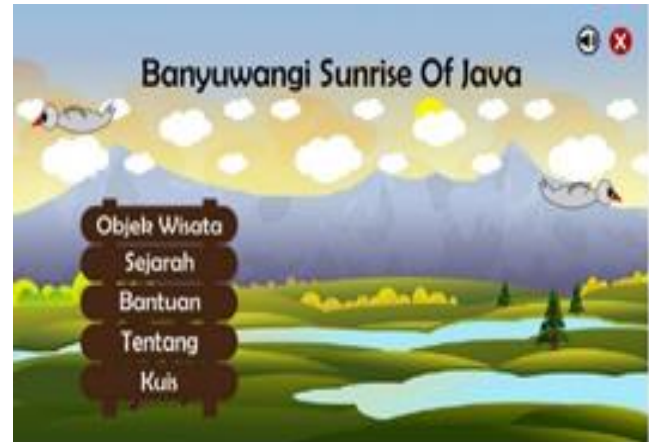

Gambar 4. Menu utama.

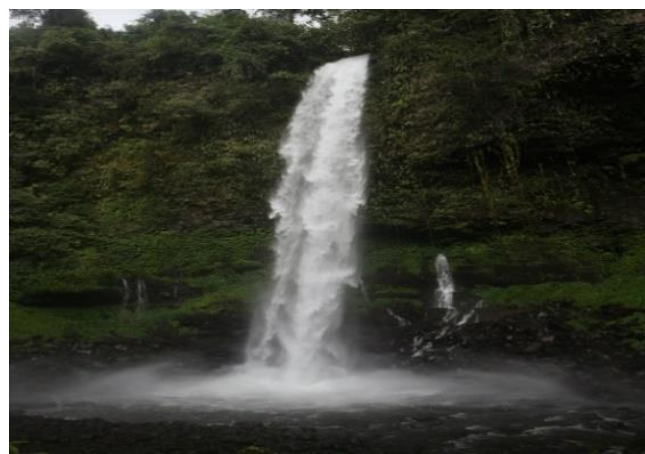

Gambar 6. Air Terjun Lider.

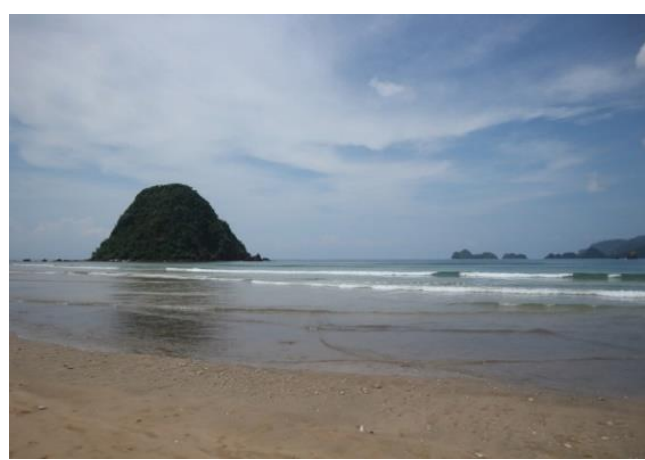

Gambar 8. Pulau Merah.

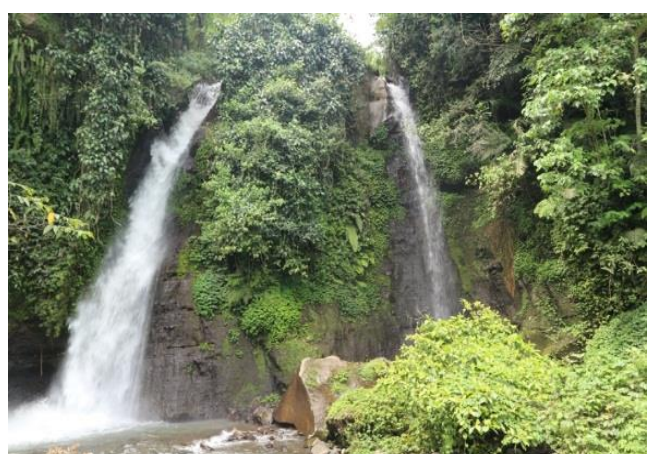

Gambar 10. Air Terjun Tirto Kemanten. 


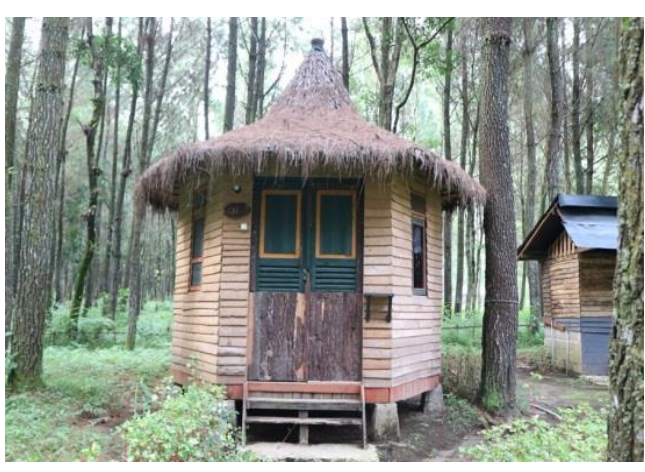

Gambar 11. Wisata Hutan Pinus Songgon.

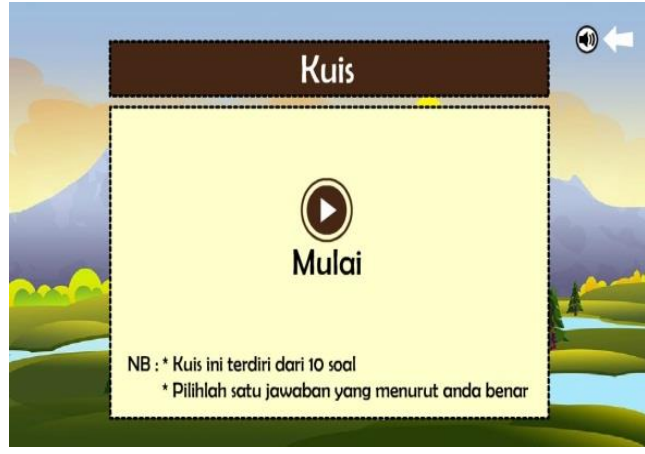

Gambar 12. Halaman awal kuis.

\subsection{Pembahasan}

Multimedia interaktif pengenalan objek wisata di Kabupaten Banyuwangi dibangun menggunakan software Adobe Flash. Dalam pengembangannya menerapkan tahapan-tahapan sebagaimana yang ada dalam model Delphi, meliputi: (1) mendefinisikan tujuan hasil penelitian, yaitu mengenalkan objek-objek wisata di Kabupaten Banyuwangi; (2) meninjau produk-produk serupa yang pernah dibangun, dan hasilnya belum ditemukan produk serupa dengan akan dibangun; (3) menentukan format ouput berupa file yang dapat dijalankan di Android dengan jangka waktu penyelesaian pembangunan 2-3 bulan; (4) menentukan konten/materi yang akan disampaikan meliputi sejarah, data/karakteristik lokasi wisata, contoh-contoh foto dan video, dan kemudian menstrukturkan dan mengurutkan materi-materi yang diperoleh secara sistematis sesuai tujuan pengenalan beserta strategi penyampaiannya; (5) mengembangkan sistem flowchart, sitemap atau sistem struktur menu dan juga storyboard (urutan tampilan slide beserta elemen-elemen multimedia yang meliputi teks, gambar/foto, video, narasi, latar musik/suara, dan animasi teks/label/objek yang diperlukan); (6) mengembangkan prototipe produk berbasis Android; dan (7) menguji/mengevaluasi formatif melalui kuesioner atau instrumen evaluasi terbatas mencakup tiga responden dari pengguna yang memahami aplikasi ini. Kuesioner memuat indikator kualitas antara lain: tujuan pembelajaran, bahasa sesuai dengan target audiensi, konten akurat dan faktual, konten selaras dengan tujuan belajar, tersedianya petunjuk operasional, konten mudah dipahami, aplikasi multimedia bersifat interaktif, penggunaan media selaras atau memadai dan antarmuka; aplikasi ini menarik secara visual serta mudah digunakan.. Langkah (8) dan (9) belum dilakukan, karena langkah tersebut diperlukan jika produk multimedia yang diproduksi akan diterapkan secara komersial dan atau digunakan pada lingkup masyarakat yang lebih luas. Oleh karenanya, hasil pengembangan multimedia pengenalan ini masih bersifat prototipe dan file hasilnya berbasis Android atau berupa file dengan ekstensi apk. Untuk dapat melanjutkan pengembangan model Delphi ini, yaitu langkah (8) dan (9), diperlukan dievaluasi produk lebih lanjut dengan melibatkan stakeholder dan juga para ahli yang kompeten yang lebih luas, guna pemutakhiran produk, baik dari sisi desain, bahasa pengantar, kualitas, kelengkapan objek-objek wisata yang ada di Banyuwangi, maupun dari sisi pendistribusiannya agar dapat diakses calon wisatawan secara lebih luas. Meskipun belum semua langkah dipenuhi, aplikasi multimedia ini secara umum telah memiliki kualitas baik. Hal ini dilihat dari hasil tes formatif pada langkah (7) atas produk multimedia yang dihasilkan.

\section{Kesimpulan dan Saran}

Prototipe multimedia interaktif pengenalan objek-objek wisata di Kabupaten Banyuwangi berbasis Android telah berhasil dibangun melalui tahapan-tahapan pengembangan multimedia pengenalan (pembelajaran) model Delphi. Prototipe yang dihasilkan menampilkan sejumlah objek-objek wisata yang meliputi: Kawah Ijen, Teluk Ijo, Pulau Merah, Air Terjun Lider, Air Terjun Tirto Kemanten, Air Terjun Kembang Arum, Sumber Mata Air Umbul Bening, Hutan Pinus Songgon, dan Rowo Bayu. Selain menampilkan objek-objek wisata, aplikasi ini juga memuat sejarah, dan arah/peta lokasi wisata serta kuis (bertipe pilihan ganda dan permainan) guna menguji pengetahuan yang telah diperoleh melalui pengenalan ini.

Aplikasi multimedia ini masih perlu penyempurnaan, baik dari sisi jumlah lokasi wisata yang belum terakomodasi, maupun dari sisi kemudahan akses yang lebih luas di situs Web, secara khusus bagi calon wisata yang ingin mengetahui lokasi-lokasi wisata di Banyuwangi. Untuk mengoptimalkan akses yang luas bagi pengunjung, diperlukan penyajian dalam dwi bahasa, yakni bahasa Indonesia dan Inggris. 


\section{Daftar Pustaka}

[1] Fahad, H.A. \& Endrayadi, E.C. 2017. Pengembangan Sektor Pariwisata Di Kabupaten Banyuwangi Tahun 2002-2013. Publika Budaya. 5,1; 28-35.

[2] Rozi, P. 2012. Perancangan Aplikasi Berbasis Multimedia Interaktif Sebagai Media Informasi Dan Promosi Pariwisata Danau Kerinci Di Kabupaten Kerinci-Jambi. Naskah Publikasi- STMIK AMIKOM- Yogyakarta. Yogyakarta.

[3] Pemda Kabupaten Banyuwangi. 2017. Guide Book Banyuwangi Tourism. Regency Culture and Tourism Service. Banyuwangi.

[4] IACBE. 2014. Bloom's Taxonomy of Educational Objectives and Writing Intended Learning Outcomes Statements. Lenexa, Kansas, USA: The International Assembly for Collegiate Business Education.

[5] Delphi Method. https://www.rand.org/topics/delphi-method.html, diakses tanggal 27 November 2019

[6] Frey, B.A. \& Sutton, J.M. 2010. A Model for Developing Multimedia Learning Projects. MERLOT Journal of Online Learning and Teaching. 6,2; 491-507.

[7] Rusli, M., Hermawan, D., \& Supuwiningsih, N.N. 2017. Multimedia Pembelajara Yang Inovatif: Prinsip Dasar dan Model Pengembangan. ANDI. Yogyakarta.

[8] Clark, R.C. \& Mayer, R.E. 2008. E-Learning and the Science Of Instruction. Second edition. San Francisco: In Print of Wiley.

[9] Situs Budaya. Sejarah Kabupaten Banyuwangi. https://situsbudaya.id/sejarah-kabupatenbanyuwangi/, di akses tanggal 24 November 2018.

[10] Andresen, B.B. \& Brink, K.V.D. 2013. Multimedia in Education: Curriculum. UNESCO-IITE. Moskow. 